\title{
Automatic Material Sorting and Storing Machine using Arduino
}

\author{
S.Siva Sai Kumar Reddy, R. Puviarasi, S.R.Boselin Prabhu
}

\begin{abstract}
Now a days sorting of materials in garbage industries area unit created manually. There is also probability of errors in sorting. We've got enforced an answer for substitution human by automatic management while not manual power. The project detects the objects totally different of various materials and segregate in 3 different boxes. By usage of sensors decreases the errors in sorting and reduces the person power. The projected system involves sensing element, IR sensor, mini limit switch for sensing weight and for sorting purpose linear motion electrical actuators area unit used.
\end{abstract}

Keywords:- sorting, storing, conveyor belt, sensors.

\section{I.INTRODUCTION}

The sorting of materials in garbage industries square measure created manually at this time days. There could also be likelihood of errors in sorting. We've enforced an answer for substitution human by automatic management while not manual power. The project detects the objects completely different of various $\}$ materials and segregate in 3 different boxes. By usage of sensors decreases the errors in sorting and reduces the person power. The projected system involves detector, IR sensor, mini limit switch for sensing weight and for sorting purpose linear motion electrical actuators square measure used [1]. The motor shaft is connected to the roller and also the conveyer belt is placed on the roller these provides sensible tension over the belt. The conveyor motors input gets from electrical device. The negative feedback circuit consists of ARDUINO board, relay interfacing board, transformer, input interfacing board, DC motors [2]. The logic used for sensors for characteristic materials is finished in program by weight and inductive means that it's sorted as metal. By weight and reflection it's sorted as glass and if solely reflection it's known as plastic. The material sorter has been designed in such the simplest way it will fulfill all the wants of the packaging industries wherever merchandise of various materials square measure factory-made. It has innumerous application like garbage industries, packaging fields. The project is intended in such the simplest way that may manufacture high productivity and may type materials while not smashup. By this packaging system becomes easier.

\section{II.BLOCK DIAGRAM \& CIRCUIT DIAGRAM}

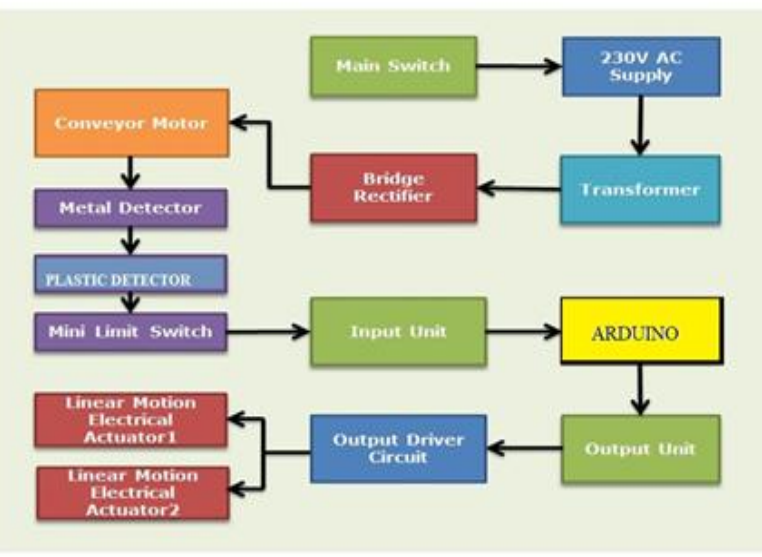

RESULTS

Fig 1block diagram of proposed system

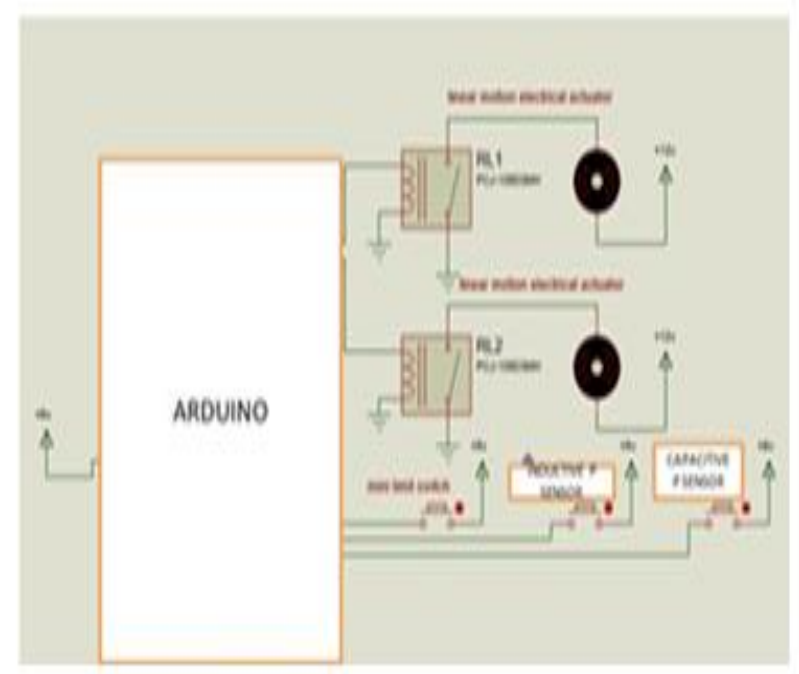

Fig 2 circuit diagram of proposed system

Revised Manuscript Received on August 14, 2019.

S.Siva Sai Kumar Reddy, Student, Saveetha School Of Engineering, SIMATS, Chennai, Tamilnadu, India.

Dr. R. Puviarasi, Asst.Professor, Saveetha School Of Engineering, SIMATS, Chennai, Tamilnadu, India.

Dr.S.R.Boselin Prabhu, Associate Professor, Department Of Ece, Surya Engineering College, Mettukadai, India. 


\section{Simulation Techniques:-}

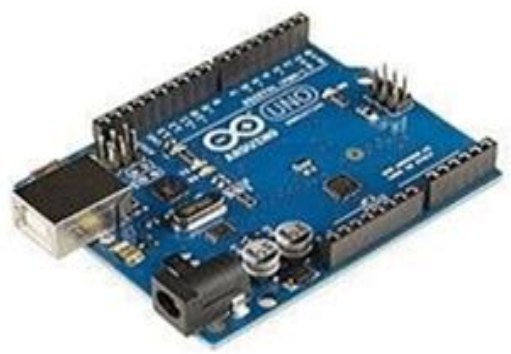

Fig 3 Arduino software

Arduino is associate degree open supply component and computer code company, project, and user community that styles and manufactures single-board microcontrollers and microcontroller kits for building digital devices.

Arduino Coding \& Electrical Linear Actuator:-

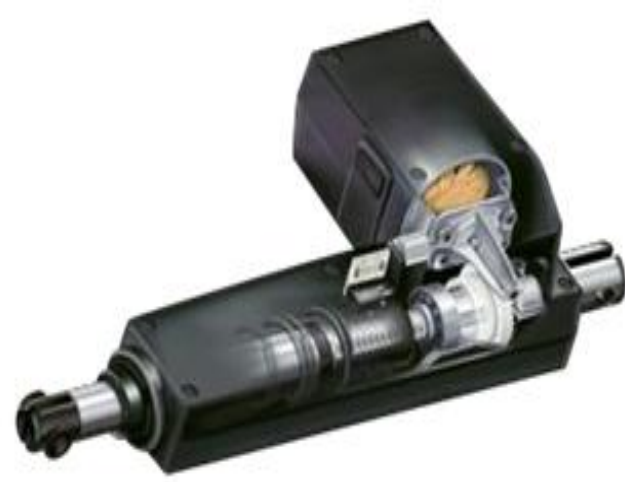

Fig 6ARDUINO Coding

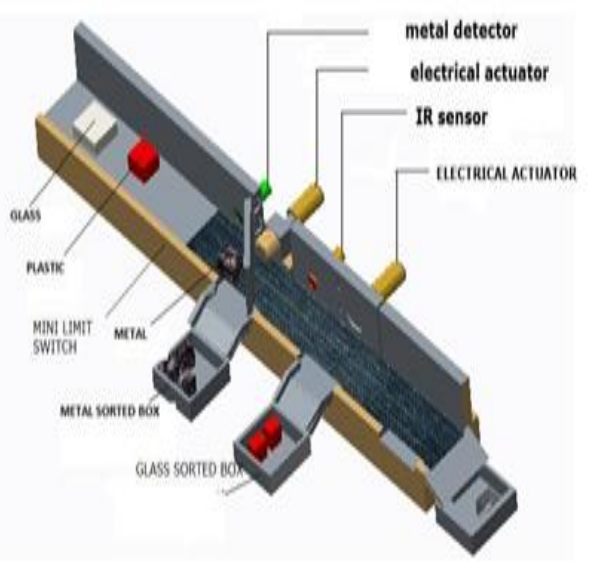

Fig 5 Actuator
Final Project Hardware Design:-

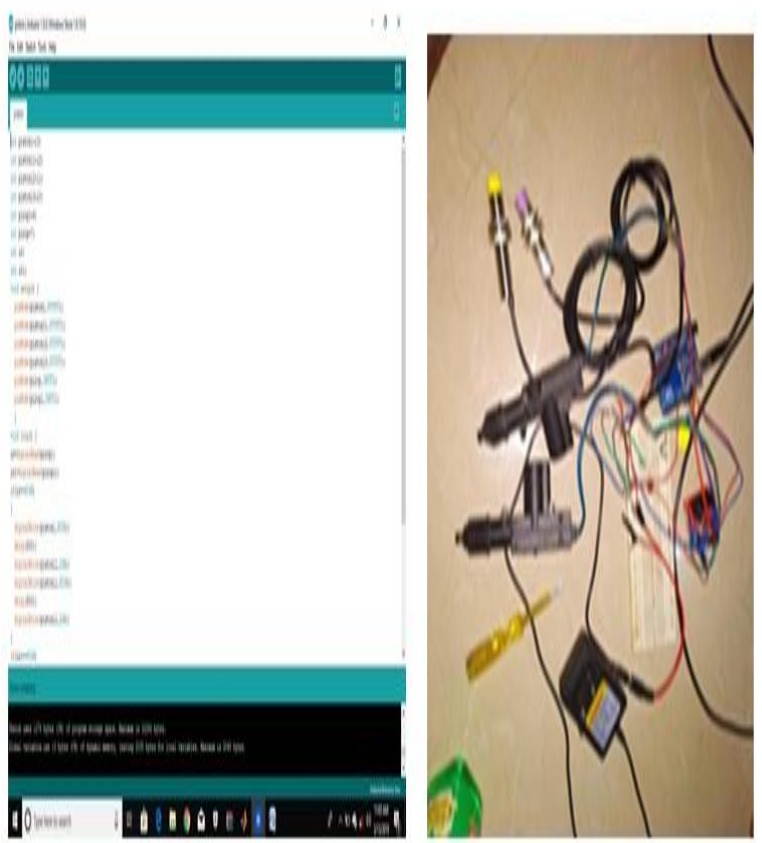

Fig 4 Project design

\section{CONCLUSION}

We have got enforced an answer for substitution human by automatic management while not manual power. The project detects the objects totally different of various materials and segregate in 3 different boxes. By usage of sensors decreases the errors in sorting and reduces the person power. The projected system involves inductive proximity sensor(for metal detector),capacitive proximate sensor(for plastic detector), mini limit switch for sensing weight and for sorting purpose linear motion electrical actuators area unit used and that we modified the system of manual power.

\section{REFERENCES}

1. Li Liu, Paul Fieguth, Dewen Hu, Yingmei Wei, and Gangyao Kuang "Fusing Sorted Random Projections for Robust Texture and Material Classification" IEEE Transactions On Circuits And Systems For Video Technology, VOL. X, NO. X, 2014

2. Babita Nanda "AUTOMATIC SORTING MACHINE USING DELTA PLC" International Journal of Innovative Research in Advanced Engineering (IJIRAE) ISSN: 2349-2163 Volume 1 Issue 7 (August 2014) 